\title{
Correction to: Effect of sertraline on complications and survival after hematopoietic stem-cell transplantation, a double-blind, placebo-controlled clinical study
}

\author{
Maria Tavakoli-Ardakani ${ }^{1}$ (D) $\cdot$ Raziyeh Kheshti $^{2} \cdot$ Maryam Mehrpooya $^{3}$
}

Published online: 27 November 2017

(c) The Japanese Society of Hematology 2017

\section{Correction to: Int J Hematol (2017) 106:832-841 \\ https://doi.org/10.1007/s12185-017-2309-y}

The correct name of the corresponding author should be "Maryam Mehrpooya", and not "Mehrpooya Maryam" as given in the original publication of the article.

The original article can be found online at https://doi. org/10.1007/s12185-017-2309-y.

Maryam Mehrpooya

m_mehrpooya2003@yahoo.com; m.mehrpoya@umsha.ac.ir

Maria Tavakoli-Ardakani

mariatavakoli@yahoo.com; mariatavakoli@sbmu.ac.ir

Raziyeh Kheshti

kheshti.raziyeh@yahoo.com; kheshti@sums.ac.ir

1 Department of Clinical Pharmacy, School of Pharmacy and Pharmaceutical Sciences Research Center, Shahid Beheshti University of Medical Sciences, Tehran, Iran

2 Department of Clinical Pharmacy, School of Pharmacy, Shiraz University of Medical Sciences, Shiraz, Iran

3 Department of Clinical Pharmacy, School of Pharmacy, Hamadan University of Medical Sciences, Hamadan, Iran 